\title{
The effect of a fresh produce incentive paired with cooking and nutrition education on healthy eating in low-income households: a pilot study
}

\author{
Angela R Fertig ${ }^{1, *} \odot$, Xuyang Tang ${ }^{2}$ and Heather M Dahlen ${ }^{3}$ \\ ${ }^{1}$ Humphrey School of Public Affairs, University of Minnesota, 301 19th Ave. S., Minneapolis, MN 55455, USA: \\ ${ }^{2}$ Centre for Global Health Research, St. Michael's Hospital, Toronto, ON, Canada: ${ }^{3}$ Mathematica Policy Research, \\ Princeton, NJ, USA
}

Submitted 27 May 2020: Final revision received 16 December 2020: Accepted 6 January 2021: First published online 12 January 2021

\begin{abstract}
Objective: This study pilot-tested combining financial incentives to purchase fruits and vegetables with nutrition education focused on cooking to increase the consumption of fruits and vegetables and improve attitudes around healthy eating on a budget among low-income adults. The goal of the pilot study was to examine implementation feasibility and fidelity, acceptability of the intervention components by participants and effectiveness.

Design: The study design was a pre-post individual-level comparison without a control group. The pilot intervention included two components, a scan card providing free produce up to a weekly maximum dollar amount for use over a 2-month period, and two sessions of tailored nutrition and cooking education. Outcomes included self-reported attitudes about healthy eating and daily fruit and vegetable consumption from one 24-h dietary recall collected before and after the intervention.

Setting: Greater Minneapolis/St. Paul area in Minnesota.

Participants: Adults ( $n$ 120) were recruited from five community food pantries. Results: Findings indicated that the financial incentive component of the intervention was highly feasible and acceptable to participants, but attendance at the nutrition education sessions was moderate. Participants had a statistically significant increase in the consumption of fruit, from an average of $1.00 \mathrm{cup} / \mathrm{d}$ to $1.78 \mathrm{cups} / \mathrm{d}(P<0.001)$, but no significant change in vegetable consumption or attitudes with respect to their ability to put together a healthy meal.

Conclusions: While combining financial incentives with nutrition education appears to be acceptable to low-income adult participants, barriers to attend nutrition education sessions need to be addressed in future research.
\end{abstract}

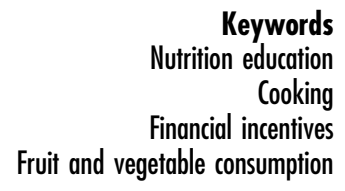

One way that individuals can improve their health is by replacing the less nutrient-dense foods in their diet with more fruit and vegetables $(\mathrm{F} / \mathrm{V})^{(1)}$. The benefits of increased $\mathrm{F} / \mathrm{V}$ consumption include having a higher micronutrient profile (i.e. vitamins and minerals) ${ }^{(2)}$, decreased risk of heart disease $^{(3)}$, decreased risk of some cancers ${ }^{(4)}$ and increased well-being ${ }^{(5,6)}$. Despite the health benefits of diets rich in $\mathrm{F} / \mathrm{V}$, the Center for Disease Control and Prevention reports that just $13 \%$ of Americans consume the amount of $\mathrm{F} / \mathrm{V}$ recommended by federal dietary guidelines ${ }^{(7)}$. In addition, low-income individuals (defined as households with incomes up to $130 \%$ of the federal poverty level) consume roughly half of an average American's daily F/V intake ${ }^{(8)}$.
Cost is a well-known and important barrier to consuming $\mathrm{F} / \mathrm{V}$ among low-income populations ${ }^{(9-11)}$. Previous research, including both national studies ${ }^{(12,13)}$ and community studies ${ }^{(14-20)}$, has found that financial incentives have a statistically significant effect on increasing the purchase and/or intake of $\mathrm{F} / \mathrm{V}$ among various subgroups of lower socio-economic individuals. However, the effect sizes have been small (on the order of a quarter cup of $\mathrm{F} / \mathrm{V}$ ) ${ }^{(12)}$. The theory of consumer choice from economics can explain this small effect; consumer decisions are based on both the consumer's budget and preferences (i.e. desire to purchase), and financial incentives only increase the budget $^{(21)}$. Thus, providing low-income individuals with 
incentives to purchase $\mathrm{F} / \mathrm{V}$ is necessary for overcoming the cost barrier, but preferences must also be addressed to substantially change behaviour.

Research suggests that individuals with lower incomes have lower preferences for $\mathrm{F} / \mathrm{V}$ for a number of reasons driven by poverty. First, compared with higher income households, individuals from low-income backgrounds are more likely to attribute health outcomes to factors outside of their control and thus are less motivated to change their health behaviours ${ }^{(22,23)}$, like healthy eating. Second, low-income families are much more likely to face numerous pressing and competing demands for their attention (e.g. financial insecurity, housing stability, transportation reliability) which reduces their ability to focus on health behaviours ${ }^{(24-26)}$. Third, low-income families prioritise purchasing food that does not go to waste, which is likely to be a small set of pantry-stable items that everyone (including children) enjoys eating (e.g. box mac and cheese), which inhibits taste formation over time ${ }^{(27,28)}$.

Finally, while all families may benefit from greater cooking confidence and skills ${ }^{(29-31)}$, research has found that less educated and lower income adults are more likely to report low cooking confidence ${ }^{(29,32)}$. Time spent cooking declined in the late 20th century among all Americans and has remained constant among low-income families for the last two decades ${ }^{(33-35)}$. At the same time, consumption of food prepared away from home has increased over time ${ }^{(36)}$. Home-cooked meals are more likely to include $\mathrm{F} / \mathrm{V}$ compared with food prepared away from home ${ }^{(37,38)}$, and several interventions involving cooking classes have shown increases in healthy eating ${ }^{(39-43)}$. Due to the above-mentioned factors that may contribute to having low preferences for $\mathrm{F} / \mathrm{V}$ in low-income families (i.e. beliefs about the effects of healthy behaviours, competing demands, limited exposure to healthy foods and lack of cooking confidence and skills), this pilot intervention incorporated experiential education focused on cooking skills and nutrition knowledge.

Several studies involving low-income populations have combined financial incentives for healthy foods with a nutrition education component ${ }^{(19,44-46)}$. The effects found in these studies were mixed, and thus further research is needed. Moreover, these prior studies had three different recruitment protocols (government food assistance programme participants attending a farmers' market ${ }^{(45)}$, mailed recruitment letters to existing supermarket customers ${ }^{(44)}$ and all store customers $\left.{ }^{(19,46)}\right)$; had four different levels of financial incentives $\left(12.5 \%\right.$ off $^{(44)}, 20 \%$ off $^{(46)}, 40 \%$ off $^{(45)}$ and $50 \%$ off $\left.^{(19)}\right)$; used four different educational components (a mailed monthly packet of individually tailored shopping lists and nutrition advice ${ }^{(44)}$, a cooking demonstration ${ }^{(19,45)}$, tasting at the farmers' market ${ }^{(45)}$ and a monthly in-store nutrition class $\left.{ }^{(46)}\right)$ and collected two different outcome measures (food purchases ${ }^{(19,44,46)}$, and self-reported consumption of soda, F/V (number of times consumed per $\mathrm{d}$ ) ${ }^{(19,45)}$ ). Thus, this pilot study was needed to determine the feasibility, fidelity and acceptability of recruitment in food pantries, of a higher incentive than that previously tested, of education at or near food pantries and of collecting 24-h dietary recalls in this population.

The Healthy Savings and Cooking (HSC) pilot intervention was developed to examine the effect of pairing financial incentives to purchase fresh produce with experiential education focused on cooking provided in the community on the healthy eating attitudes and behaviours of lowincome families. We collaborated with a scan card vendor, community food pantries and University Extension Services to implement and evaluate a fresh produce incentive scan card coupled with two education sessions: a grocery store tour focused on how to shop for fresh produce and healthy foods, and a cooking class led by a professional chef, where participants created three produce-oriented meals. The primary goals of the pilot study were to examine the implementation feasibility and fidelity, and the acceptability of the intervention components by participants; a secondary objective was to examine the effectiveness of the intervention. Feasibility and fidelity were measured by scan card use and attendance at education sessions. Acceptability was assessed via participant ratings of the intervention components. Finally, effectiveness was evaluated by testing the hypotheses that, after the HSC pilot intervention, both $\mathrm{F} / \mathrm{V}$ intake and attitudes around healthy eating on a budget would improve for study participants.

\section{Methods}

The HSC intervention was piloted in the spring of 2016 in the greater Minneapolis/St. Paul area. The study design was a pre-post individual-level comparison without a control group. In collaboration with the food pantry partners, we decided against having a control group for the pilot study given that the primary focus was on feasibility, fidelity and acceptability of the intervention.

\section{Participants}

One hundred and twenty adults were recruited from five community food pantries in Minnesota by case managers at the food pantries. The five food pantries involved had directors who volunteered to participate in the study at a community meeting convened by a state-wide hunger relief organisation. Three of the food pantries are located in the Twin Cities metro area, one is located in an outlying community adjacent to the Twin Cities with a population of $<20000$ people and one is located in a city with a population of about 40000 people located 2 h outside of the Twin Cities area.

The sample size of 120 was selected in partnership with the community food pantries who felt this number was feasible. A power analysis indicated that with a sample size of 100 (assuming 15-20\% attrition), the study had an $80 \%$ 
probability of detecting an increase in fruit or vegetable consumption of 0.75 cups. All adults visiting the partner food pantries were approached in person about the study by case managers until the recruitment goal of twenty-four per pantry was achieved. Inclusion criteria were being a food pantry client (which required having an income of $<200 \%$ of the federal poverty level, or being in crisis), being at least 18 years of age and reporting that they were able to get to and shop at a grocery store that accepted the scan card. Participants were excluded from the study if they were planning to leave the area in the next 2 months or if they did not speak English or Spanish.

\section{Intervention}

The HSC pilot intervention included two components, a Healthy Savings Program ${ }^{\circledR}$ scan $\operatorname{card}^{(47)}$ for use over a 2-month period, and two sessions of tailored nutrition and cooking education adapted from Cooking Matters for Adults ${ }^{\circledR}$, a nationally recognised cooking curriculum targeted at low-income families ${ }^{(48)}$. Cooking Matters was chosen because the curriculum focuses on helping lowincome families make healthy and affordable food choices and teaching families on limited food budgets to shop for and cook healthy meals. This specific scan card is typically given to individuals through their health insurance plans and provides weekly discounts on branded healthy food items (e.g. canned beans). For this pilot intervention, scan cards were also programmed so that participants received for free fresh produce up to a maximum benefit amount each week. Food pantries were randomised to a $\$ 10, \$ 15$ and $\$ 20$ maximum weekly incentive for their participants. As a result, twenty-four participants received $\$ 10$ per week, forty-eight received $\$ 15$ per week and forty-eight received $\$ 20$ per week on their card. Although the produce benefit terminated at the end of the intervention, weekly discounts on branded items continued to be available to all participants indefinitely. These scan cards permitted tracking of where and when participants shopped and the amount of the fresh produce benefit used each time the card was scanned.

In addition to receiving the scan card, participants signed up to attend a 1 -h grocery store tour and a 2 -h cooking class. The grocery store tour followed the format of the 'At the Store' class that is part of the 6-week Cooking Matters for Adults ${ }^{\circledR}$ curriculum ${ }^{(49)}$. The objective of the grocery store tour was to learn how to stretch budgets to include healthy foods by buying seasonal $\mathrm{F} / \mathrm{V}$, picking the best $\mathrm{F} / \mathrm{V}$, comparing unit prices and weighing fresh produce, and reading food labels to find whole-grain, low-sugar, low-fat and low-salt foods. Nutrition educators from the University of Minnesota Extension Services trained to provide the Cooking Matters ${ }^{\circledR}$ curriculum met participants at a designated store at a particular time. The educator provided each participant with a booklet of grocery shopping tips and recipes to take home and walked the participants around the store starting with the fresh produce section. The tour ended with a $\$ 10$ challenge where participants chose ingredients for a healthy meal for their family for under $\$ 10$ (gift card provided) with guidance and substitution suggestions from the nutrition educator. The grocery store tours were held at the nearest store to each food pantry that accepted the scan card. There were ten grocery store tours offered; two tours for each pantry (one morning and one evening class) were scheduled approximately 2 weeks after the recruitment week for that pantry.

The cooking class portion of the Cooking Matters for Adults ${ }^{\circledR}$ curriculum was adapted for the intervention. The main objectives of the cooking class were the same as the original curriculum: to learn how to prepare healthy meals loaded with fresh produce and to learn food safety and cooking tips from a professional chef (e.g. how to hold a knife, peel an onion or dice a mango) to increase cooking confidence and enjoyment. A few additional objectives were also added. First, we aimed to expose participants to healthy foods they might not often try (e.g. salmon, some vegetables $)^{(27,28)}$. Second, because time ${ }^{(11,50)}$, $\operatorname{cost}^{(9-11)}$ and waste avoidance ${ }^{(27,28)}$ are important barriers to healthy eating for low-income families, we altered the curriculum so that participants would learn how to prepare multiple meals at one time using shared ingredients across recipes and we condensed the five cooking sessions covering one meal each in the original curriculum into one session covering three meals. Finally, we provided each participant with a kitchen supplies kit to take home along with three prepared meals ${ }^{(51)}$, where the original curriculum sends home unprepared groceries only.

The cooking classes were held either at the food pantry (if on-site kitchen facilities were available) or at a nearby location like a church or teen centre. There were ten cooking classes offered; two classes for each pantry (one morning and one evening class) were scheduled approximately 4 weeks after the recruitment week for that pantry. The cooking class was led by a professional chef with the help of at least one assistant. Chef 1 led six of the classes, Chef 2 led three of the classes and one volunteer Chef led one class. All three chefs followed the same course outline. Separate cooking stations with a single burner, sauté pan, a kitchen supplies kit and ingredients for three recipes were set up for the chef and each participant.

Three meals were prepared during the class: salmon with a mango salsa, Moroccan chicken with apples and raisins, and a vegetable bean soup. At the end of the class, the prepared meals were packaged in plastic bags suitable for freezing and taken home. Meals prepared by the chef were divided up for taste testing during the class. Recipe cards provided directions for freezing and re-heating the meals. The kitchen supplies kit, which each participant took home after the class, included two knives, a chopping mat, a meat thermometer, wooden spoons, a hot pad, two kitchen towels, four mixing bowls, a strainer and measuring cups and spoons. 


\section{Measurements}

A survey and one 24-h dietary recall were conducted at the time of recruitment and post-intervention ( 2 months after recruitment). The survey was administered in-person by food pantry case managers. The 24-h dietary recalls were conducted online with computers at the food pantry using the National Cancer Institute Automated Self-Administered 24-hour Dietary Assessment Tool (ASA24) ${ }^{(52)}$. The ASA24 is designed to be self-administered by the respondent; validation and evaluation studies have found close concordance between the ASA24 system and interviewer-administered dietary recalls ${ }^{(53-55)}$. The scan card vendor provided data on all $\mathrm{F} / \mathrm{V}$ purchases where the scan card was used. The following measures were captured through data collection.

\section{Baseline demographic, socio-economic and bealth measures}

At baseline, participants were asked their age, gender, race/ethnicity, foreign-born status, highest education level completed, height and weight, and household composition information (household size, ages and gender of other household members, and relation to respondent of other household members). To capture socio-economic status, income and public programme participation (e.g. the Supplemental Nutrition Assistance Program (SNAP) or the Special Supplemental Nutrition Program for Women, Infants, and Children (WIC)), information was collected, as well as responses to a series of questions about food security. The baseline survey collected self-reported height and weight (which we used to calculate BMI), whether participants had ever been told that they had specific chronic health conditions, and whether they had serious impairments or limitations in activities of daily. The list of chronic conditions queried included stroke, heart attack, heart disease, hypertension, diabetes, pre-diabetes, asthma, chronic lung disease, arthritis, cancer or psychiatric problems. The list of physical or cognitive limitations queried included serious hearing difficulty, serious difficulty seeing even when wearing glasses, serious difficulty concentrating, serious difficulty walking or climbing stairs, difficulty dressing or bathing and difficulty doing errands alone, like shopping.

\section{Measures of feasibility, fidelity and acceptability}

We assessed feasibility and fidelity of the implementation of the intervention by the number of weeks the scan card was used by participants and the percentage of the benefit received that was spent, as well as by attendance at the two nutrition education sessions. We assessed acceptability of the intervention via participant ratings of the scan card and each of the education sessions on a 5-point Likert scale (from really liked to really did not like). We also asked participants five yes/no questions about whether they were making changes as a result of the scan card and the cooking class. Finally, we asked ten questions about making changes after the grocery store tour and/or the cooking class where the answer choices were 'This idea is not for me,' 'I don't know how to do this,' 'I want to try to do this in the next 6 months,' 'I have started doing this since the tour/class,' 'I do this more than I did before the tour/class' or 'I already did this before the tour/class and haven't changed.' The participant ratings are only available for participants who responded to the follow-up survey. Questions about the card were only asked of those who used the card, and questions about each education session were only asked of those who attended the session.

\section{Fruit and vegetable intake}

One 24-h dietary recall was conducted at baseline and then again at follow-up. The number of cups of fruits consumed in a 24-h period and the number of cups of vegetables consumed in a 24-h period after the intervention were compared with the baseline amounts. Dietary recalls are considered a gold standard for measuring food and nutrient intake among adults and are preferable to food records in study populations where literacy may be low ${ }^{(56)}$. The prepost analysis is restricted to participants who completed both dietary recalls.

\section{Attitudes about healthy eating on a budget}

Attitudes about healthy eating on a budget were assessed via a 'financially defeated' construct captured with responses to four questions (Cronbach $\alpha=0 \cdot 71$ ), which are a subset of a questionnaire used to capture nutrition attitudes in a prior study ${ }^{(57)}$. The four survey questions were asked at baseline and follow-up. Participants responded to each question on a 5-point Likert scale: strongly disagree $(-2)$, disagree (-1), unsure (0), agree (1) or strongly agree (2). The degree to which the participant identifies as financially defeated is measured by the sum of the responses to the following four questions: 'The cost of food limits what kinds of food I buy,' 'Meat is too expensive to eat daily,' 'Fruits and vegetables are too expensive to eat daily' and 'I can make a nutritious meal within my budget.' The response to the last question was reverse-coded before being summed with the other three questions. This prepost analysis is restricted to participants who completed a baseline and follow-up survey.

\section{Statistical analyses}

Feasibility, fidelity and acceptability were evaluated with descriptive statistics. Correlates of scan card usage and number of education sessions attended were examined by ordinary least squares and ordered logistic regression, respectively, to determine which types of participants were most likely to adhere to the full intervention protocol. Changes in outcomes between baseline and follow-up responses were assessed using paired $t$ tests (unadjusted) and generalised linear mixed models with adjustments for recruitment food pantry, age, gender, household 
composition, foreign-born status, race/ethnicity, education, family income, employment status, food insecurity status, participation in SNAP and/or WIC, BMI, the presence of any limitations in activities of daily living, and the presence of any chronic conditions.

Because participants were not forced to use the card or attend the classes, a modified intention-to-treat analytic strategy is employed ${ }^{(58)}$. Specifically, we made every effort to obtain follow-up outcome data on all participants, but there was loss of subjects due to attrition from the study. We did not impute outcome data for those lost to attrition, but instead restricted pre-post analyses to participants with follow-up data. Because there was attrition between baseline and follow-up, we compared the analysis sample (i.e. the participants with complete data at follow-up) to the sample lost to attrition.

\section{Results}

\section{Description of participants}

Only $12.5 \%$ of the 120 participants recruited at baseline were seniors, while $44.2 \%$ were adults under age 45 and $43.3 \%$ were age 45-64 (Table 1). A small minority of participants were men $(17 \cdot 4 \%)$. The majority had children under age 18 living at home (61.7\%), while only $18.3 \%$ of participants lived alone. Slightly more than half of participants were white, 28.6\% were Black (either AfricanAmerican or African immigrants), 9.8\% were Latino and $8.9 \%$ were Asian. The majority of participants had a high school degree only (54.2\%), and $30 \%$ completed some post-secondary education. Mean annual family income was $\$ 19684$, and $35.8 \%$ were currently working. Only a quarter of the sample had high food security, while $7.6 \%$ had very low food security. Slightly more than half currently received SNAP benefits, and 16.1\% currently received WIC. The mean BMI was 30.0. Thirty-nine percentage of participants had at least one limitation in activities of daily living, while $69.7 \%$ had at least one chronic health condition.

Of the 120 participants recruited, ninety-one completed both the 24-h dietary recall and the survey at follow-up, resulting in an attrition rate of $24 \%$. Eighteen of the twenty-nine lost to attrition (or $62 \%$ ) were recruited at one of the five food pantries. This food pantry serves a high-poverty African-American neighbourhood. The participants recruited from this food pantry had half the average family income as at the other partner food pantries. The case manager from this food pantry also expressed that the community relationship with the closest participating grocery store was poor, suggesting that participants may have been reluctant to shop there. As a result, the analysis sample differs from the baseline sample by foreign-born status, racial/ethnic composition and family income (Table 1 ). The other significant differences between the analysis and baseline samples include age, education, WIC receipt
Table 1 Participant characteristics

\begin{tabular}{|c|c|c|}
\hline Characteristics & $\begin{array}{l}\text { Baseline sample } \\
\quad(n 120)\end{array}$ & $\begin{array}{c}\text { Analysis } \\
\text { sample } \\
(n 91)\end{array}$ \\
\hline Age $18-44$ years & $44.2 \%$ & $38.4 \% *$ \\
\hline Age $45-64$ years & $43.3 \%$ & $47.3 \%$ \\
\hline Age $65+$ years & $12.5 \%$ & $14.3 \%$ \\
\hline Men & $17.4 \%$ & $19.3 \%$ \\
\hline $\begin{array}{l}\text { Any children under age } 18 \text { living } \\
\text { at home }\end{array}$ & $61.7 \%$ & $58 \cdot 2 \%$ \\
\hline Live alone & $18.3 \%$ & $19 \cdot 8 \%$ \\
\hline Born in USA & $63.3 \%$ & $71.4 \%$ * \\
\hline White & $50.9 \%$ & $59.0 \%$ * \\
\hline Black & $28.6 \%$ & $20.5 \%$ * \\
\hline Latino & $9.8 \%$ & $9.6 \%$ \\
\hline Asian & $8.9 \%$ & $8.4 \%$ \\
\hline Other race & $1.8 \%$ & $2.4 \%$ \\
\hline Less than HS degree & $15 \cdot 8 \%$ & $13.2 \%$ \\
\hline HS degree & $54.2 \%$ & $51.6 \%$ \\
\hline More than HS degree & $30.0 \%$ & $35.2 \%$ * \\
\hline Annual family income & $\$ 19684$ & $\$ 21035^{*}$ \\
\hline $\begin{array}{l}\text { Currently working full or } \\
\text { part-time }\end{array}$ & $35.8 \%$ & $34.1 \%$ \\
\hline High food security & $26.9 \%$ & $27.5 \%$ \\
\hline Marginal food security & $51.3 \%$ & $50.5 \%$ \\
\hline Low food security & $14.3 \%$ & $14.3 \%$ \\
\hline Very low food security & $7.6 \%$ & $7.7 \%$ \\
\hline Currently receiving SNAP & $52.1 \%$ & $50.6 \%$ \\
\hline Currently receiving WIC & $16.1 \%$ & $12 \cdot 2 \%$ * \\
\hline BMI & $30 \cdot 0$ & 29.8 \\
\hline $\begin{array}{l}\text { Any limitations in activities } \\
\text { of daily living } \dagger\end{array}$ & $38.7 \%$ & $43 \cdot 3 \%$ \\
\hline $\begin{array}{l}\text { Any chronic health } \\
\text { problems } \ddagger\end{array}$ & $69.7 \%$ & $75.5 \%$ * \\
\hline
\end{tabular}

HS, high school; SNAP, Supplemental Nutrition Assistance Program; WIC, Special Supplemental Nutrition Program for Women, Infants, and Children.

*Analysis sample is significantly different from those lost to attrition at $P<0.05$. †Limitations in activities of daily living included serious hearing difficulty, serious difficulty seeing even with glasses, serious difficulty concentrating/remembering/ making decisions, serious difficulty walking or climbing stairs, difficulty dressing or bathing and difficulty doing errands alone like visiting doctor or shopping. $\ddagger$ Chronic health problems include ever having had a stroke, heart attack, heart disease, hypertension/high blood pressure, asthma, chronic lung disease, diabetes/high blood sugar, prediabetes, arthritis/rheumatism, cancer (besides skin cancer) or an emotional/nervous/psychiatric problem.

status and the presence of chronic health conditions (Table 1). There were no significant differences by gender, household composition, employment status, SNAP status, food security status or physical/cognitive limitation status.

\section{Feasibility and fidelity - programme usage}

Of the 120 participants, $93 \%$ used the scan card at a grocery store at least once over the 2-month intervention period (Table 2). In the first week after recruitment, $75 \%$ of the 120 participants used the scan card (Fig. 1). The rate of usage rose slightly in week 2 , when the grocery store tour occurred; participants attending the tour used their card during the tour. The rate of usage declined in weeks 3 and 4 and then rose in week 5 to $71 \%$, which was immediately after the cooking class occurred. Card usage slightly declined such that $58 \%$ used the card in the 8 th week of the intervention. When a participant used the card in a given week (regardless of the week), they spent $93 \%$ of their benefit on average (not shown). That is, if a participant 
Table 2 Programme usage

\begin{tabular}{|c|c|c|c|c|}
\hline & \multicolumn{2}{|c|}{$\begin{array}{l}\text { Baseline } \\
\text { sample } \\
(n 120)\end{array}$} & \multicolumn{2}{|c|}{$\begin{array}{c}\text { Analysis } \\
\text { sample } \\
(n 91)\end{array}$} \\
\hline & Mean & SD & Mean & SD \\
\hline Benefit per week & $\$ 16 \cdot 0$ & 3.76 & $\$ 15 \cdot 4^{*}$ & 3.59 \\
\hline Used the scan card ever & $93 \%$ & 0.26 & $98 \% *$ & 0.15 \\
\hline Available weeks scan card was used $\dagger$ & $77 \%$ & 0.26 & $82 \%{ }^{*}$ & 0.21 \\
\hline $\begin{array}{l}\text { Available fresh produce benefit } \\
\text { spent† }\end{array}$ & $72 \%$ & 0.26 & $76 \% *$ & 0.21 \\
\hline Attended grocery store tour & $52 \%$ & 0.50 & $60 \% *$ & 0.49 \\
\hline Attended cooking class & $56 \%$ & 0.50 & $70 \%{ }^{*}$ & 0.46 \\
\hline Attended neither education offering & $33 \%$ & 0.47 & $20 \%{ }^{*}$ & 0.40 \\
\hline Attended both education offerings & $40 \%$ & 0.49 & $51 \%{ }^{*}$ & 0.50 \\
\hline
\end{tabular}

*Analysis sample is significantly different from those lost to attrition at $P<0.05$. $\dagger$ Available weeks is the number of weeks between recruitment and the end of the intervention; for these two measures, the percentages only include those who used the card ever ( $n 111$ for the baseline sample and $n 90$ for the analysis sample).

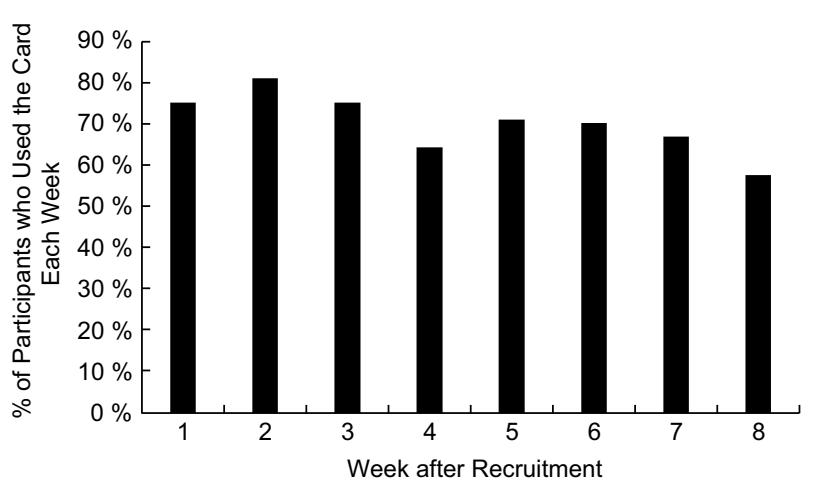

Fig. 1 Scan card usage by week

with a $\$ 15$ benefit used the card in a given week, they spent $\$ 14$ of their benefit that week.

Among those who used the card at least once, participants used the card on average $77 \%$ of the weeks available and spent $72 \%$ of the benefit they had available (Table 2). That is, the average participant used the card 6 out of the 8 weeks that they received the fresh produce incentive and bought $\$ 86$ in fresh produce with their fresh produce benefit over those 8 weeks if their weekly benefit level was $\$ 15$ per week. There were no significant differences in scan card usage rates by benefit level ( $\$ 10 v . \$ 15 v$. $\$ 20$ ). Attendance at the education sessions was $52 \%$ for the grocery store tour and $56 \%$ for the cooking class (Table 2). Two-thirds of participants attended at least one and $40 \%$ of the sample attended both sessions. Participants who stayed in the programme through follow-up had higher rates of programme usage; $98 \%$ used the card at least once, $80 \%$ attended at least one of the education sessions and $51 \%$ attended both.

Regression analysis (Table 3) indicates that the most important predictor of high programme usage was education. The percentage of the fresh produce benefit used was significantly lower among participants who were currently working. The number of nutrition sessions attended was significantly lower among participants receiving WIC. No significant associations between programme usage and age, gender, household composition, immigrant status, race/ethnicity, family income, food insecurity status, SNAP receipt, BMI or health status were observed.

\section{Acceptability - participant ratings}

Of the ninety card users who completed the follow-up survey, nearly all (99\%) really liked or liked the fresh produce benefit (Table 4). Ninety percent of the card users said they buy more $\mathrm{F} / \mathrm{V}$ than at baseline, and $84 \%$ said the card caused them to eat fresh produce they otherwise would not have purchased.

Of the fifty-five respondents who attended the grocery store tour, $89 \%$ really liked or liked the tour, and as a result of the tour, $73 \%$ had begun (or planned to begin) incorporating at least one grocery shopping skill they learned in the tour (from a list of seven possible skills). Of the sixty-four cooking class attendees who completed the follow-up survey, nearly all (98\%) responded that they liked or really liked the cooking class and $86 \%$ found they enjoyed cooking more after attending the class, with three-fourths of them having tried new recipes with fresh produce. Eighty-three percentage had begun (or planned to begin) incorporating at least one cooking skill they learned in the class (from a list of three possible skills).

\section{Effectiveness - pre-post results}

Unadjusted pre-post comparisons showed an increase in the consumption of fruits, from an average 1.00 equivalent servings to 1.78 servings (Table 5 ). The results also show a slight decrease in the responses that indicate that participants identify as 'financially defeated.' There was no change in vegetable consumption over time.

When adjustments for baseline demographic, socioeconomic and health characteristics are made, the results are similar (Table 6). The consumption of fruit is 0.79 cups higher after the intervention than before, the 'financially defeated' score after the intervention is half a point lower than before, but vegetable consumption after the intervention is not different from before.

\section{Discussion}

This study examined the implementation feasibility and fidelity, the acceptability of the intervention components to participants and the effectiveness of the HSC pilot intervention. Results of this pilot study showed that food pantries are promising locations for recruiting and intervening on low-income, food-insecure populations. Results also indicate that the financial incentive component of the intervention is highly feasible and acceptable to lowincome participants. It adds to a limited body of work that focuses on the effect of financial incentives combined with 
Table 3 Correlates of programme usage (baseline sample $n$ 120)

\begin{tabular}{|c|c|c|c|c|}
\hline \multirow[b]{2}{*}{ Dependent variables } & \multicolumn{2}{|c|}{$\begin{array}{l}\text { Percent of available fresh } \\
\text { produce benefit used }\end{array}$} & \multicolumn{2}{|c|}{$\begin{array}{l}\text { Number of nutrition educa- } \\
\text { tion offerings attended }\end{array}$} \\
\hline & Coefficient & $95 \% \mathrm{Cl}$ & Coefficient & $95 \% \mathrm{Cl}$ \\
\hline \multicolumn{5}{|l|}{ Age group $($ ref $=18-44)$} \\
\hline Age $45-64$ & 0.023 & $-0.120,0.167$ & -0.674 & $-1.688,0.340$ \\
\hline Age $65+$ & -0.088 & $-0.344,0.168$ & -1.285 & $-3.083,0.514$ \\
\hline Male & -0.009 & $-0.183,0.166$ & -0.749 & $-1.943,0.444$ \\
\hline Any children & 0.003 & $-0.191,0.196$ & -0.650 & $-2.033,0.732$ \\
\hline Live alone & -0.046 & $-0.259,0.166$ & 0.277 & $-1.247,1.800$ \\
\hline Born in USA & -0.067 & $-0.247,0.112$ & -1.001 & $-2.266,0.265$ \\
\hline \multicolumn{5}{|l|}{ Race/Ethnicity (ref = non-Latino white) } \\
\hline African-American & 0.057 & $-0.249,0.135$ & 0.497 & $-0.843,1.837$ \\
\hline Latino & -0.092 & $-0.340,0.156$ & -0.604 & $-2.481,1.273$ \\
\hline Asian & 0.035 & $-0.252,0.322$ & 1.828 & $-0.200,3.856$ \\
\hline Other race & 0.205 & $-0.278,0.689$ & 0.634 & $-2.536,3.805$ \\
\hline \multicolumn{5}{|l|}{ Education completed (ref $=$ high school degree) } \\
\hline Less than high school degree & -0.021 & $-0.227,0.185$ & $-1 \cdot 657^{\star}$ & $-3.185,-0.128$ \\
\hline More than high school degree & $0.171^{*}$ & $0.018,0.324$ & $1.552^{\star *}$ & $0.420,2.684$ \\
\hline Log (family income) & -0.004 & $-0.044,0.037$ & 0.156 & $-0.163,0.475$ \\
\hline Currently working full or part-time (ref = Unemployed, out-of-labour force) & $-0.151^{*}$ & $-0.293,-0.009$ & -0.095 & $-1.079,0.890$ \\
\hline \multicolumn{5}{|l|}{ Food security status (ref = High food security) } \\
\hline Marginal & -0.080 & $-0.246,0.085$ & -0.765 & $-1.919,0.389$ \\
\hline Low or very low food security & -0.106 & $-0.309,0.097$ & -0.716 & $-2.103,0.672$ \\
\hline Currently receiving SNAP & 0.056 & $-0.083,0.195$ & 0.807 & $-0.199,1.813$ \\
\hline Currently receiving WIC & 0.039 & $-0.164,0.242$ & $-1.470^{*}$ & $-2.913,-0.028$ \\
\hline $\mathrm{BMI}$ at baseline & -0.000 & $-0.010,0.010$ & 0.069 & $-0.004,0.141$ \\
\hline Any activities of daily living limitations & 0.044 & $-0.102,0.190$ & 0.552 & $-0.481,1.585$ \\
\hline Any chronic health problems & -0.064 & $-0.229,0.101$ & -0.012 & $-1.194,1.170$ \\
\hline
\end{tabular}

SNAP, Supplemental Nutrition Assistance Program; WIC, Special Supplemental Nutrition Program for Women, Infants, and Children.

OLS coefficients reported in column 1 and ordered logit coefficients reported in column 3 . Food shelf indicators were also included.

${ }^{*} P<005$.

${ }^{\star \star} P<0.01$.

Table 4 Participant ratings

Percentage of respondents who said the following

Scan card users $(n 90)$

Really liked or liked the healthy savings fresh produce benefit $\quad 98.9$

$\begin{array}{lr}\text { Found the card very easy or easy to use } & 92.2\end{array}$

$\begin{array}{lr}\text { Eat more F/V than at baseline } & 90.1\end{array}$

Card caused them to buy fresh produce they would not otherwise have bought $\quad 84.4$

Grocery store tour attendees ( $n 55)$

$\begin{array}{ll}\text { Really liked or liked the grocery store tour } & 88.7\end{array}$

$\begin{array}{lr}\text { Have made or will start at least } 1 \text { of } 7 \text { changes since the tour } & \\ \end{array}$

Cooking class attendees $(n 64)$

Really liked or liked the cooking class $\quad 98.4$

\begin{tabular}{lr} 
Enjoy cooking more & 86.2 \\
\hline
\end{tabular}

Have tried new recipes with fresh produce $r$

$\begin{array}{lr}\text { Have prepared at least one class recipe at home } & 46 \cdot 2\end{array}$

$\begin{array}{lr}\text { Have done or will start at least } 1 \text { of } 3 \text { changes since the class } \dagger & 82 \cdot 8\end{array}$

*Tour skills include comparing unit prices to find the best deal at the grocery store, weighing fresh produce to estimate cost, reading ingredient lists to find whole grains, comparing food labels to make healthy choices, looking for low-salt options, looking for low-sugar and high-fibre cereals, looking for low-fat options.

†Class skills include making home-made meals 'from scratch' using mainly basic whole ingredients, adjusting meals to be healthier, and preparing more than one meal at a time and freezing the extras for later.

nutrition education on $\mathrm{F} / \mathrm{V}$ consumption of low-income individuals.

This HSC pilot intervention was an innovative collaboration between multiple non-profit organisations (Medica Research Institute, the University of Minnesota, United Way, SNAP-Ed, and five community food pantries) and a for-profit business (Solutran Inc.). The discussion between community partners and the researchers not only identified food pantry users as the targeted low-income population but also enhanced the implementation of the study. Researchers from Medica Research Institute and the University of Minnesota designed and carried out the study with the insights from staff at SNAP-Ed who regularly run Cooking Matters curriculum in the Twin Cities community. United Way donated all foods used in this intervention and helped the researchers to understand the needs and hardships of the low-income community. Staff at local food pantries were instrumental in recruitment and participant 
Table 5 Unadjusted pre-post comparisons ( $n$ 91)

\begin{tabular}{|c|c|c|c|c|c|c|c|}
\hline & \multicolumn{7}{|c|}{ Analysis sample ( $n$ 91) } \\
\hline & \multicolumn{2}{|c|}{ Pre } & \multicolumn{2}{|c|}{ Post } & \multicolumn{3}{|c|}{ Difference } \\
\hline & Mean & SD & Mean & SD & Mean & $95 \% \mathrm{Cl}$ & $P$-value \\
\hline Daily servings of fruit & 1.00 & 1.36 & $1 \cdot 78$ & 1.71 & 0.79 & $1.09,0.49$ & 0.000 \\
\hline Daily servings of vegetables & 1.74 & 1.67 & 1.71 & 1.26 & -0.04 & $-0.40,0.33$ & 0.846 \\
\hline Agreement that cost of food limits what kinds of foods I buy & $89 \%$ & 0.31 & $87 \%$ & 0.34 & -0.02 & $-0.12,0.07$ & 0.640 \\
\hline Agreement that meat is too expensive to eat daily & $73 \%$ & 0.45 & $66 \%$ & 0.48 & -0.07 & $-0.18,0.05$ & 0.259 \\
\hline Agreement that $F / V$ are too expensive to eat daily & $67 \%$ & 0.47 & $63 \%$ & 0.49 & -0.04 & $-0.16,0.07$ & 0.453 \\
\hline Agreement that I can make a nutritious meal within my budget & $66 \%$ & 0.48 & $75 \%$ & 0.43 & 0.09 & $-0.03,0.21$ & $0 \cdot 131$ \\
\hline Financially defeated score (sum of 4 items, last item reverse coded) & $2 \cdot 26$ & 3.06 & 1.73 & 2.85 & -0.54 & $-1.17,0.09$ & 0.093 \\
\hline
\end{tabular}

F/V, fruit and vegetables.

Table 6 Adjusted pre-post comparisons ( $n$ 91)

\begin{tabular}{|c|c|c|c|c|c|c|}
\hline \multirow[b]{2}{*}{ Dependent variable } & \multicolumn{2}{|c|}{ Daily servings of fruit (cups) } & \multicolumn{2}{|c|}{ Daily servings of vegetables (cups) } & \multicolumn{2}{|c|}{ Financially defeated score } \\
\hline & Coefficient & $95 \% \mathrm{Cl}$ & Coefficient & $95 \% \mathrm{Cl}$ & Coefficient & $95 \% \mathrm{Cl}$ \\
\hline After the intervention & 0.787 & $0.489,1.085$ & -0.036 & $-0.400,0.327$ & -0.538 & $-1 \cdot 160,0.083$ \\
\hline
\end{tabular}

Generalized linear mixed model coefficients reported in columns 1, 3 and 5. Regressions adjusted for recruitment food pantry, age, gender, household composition, foreignborn status, race/ethnicity, education, family income, employment status, food insecurity status, participation in SNAP and WIC, BMI, number of limitations in activities of daily living and number of chronic conditions.

retention. With the help from the collaborations in recruitment, participant retention and identifying relevant intervention elements, this pilot intervention resulted in higher participation than previous studies with similar intervention elements. Nearly all participants used the card and used it frequently. Although the attendance of the education sessions was moderate overall (slightly more than half of the participants attended the cooking class), it was higher than what has been observed in other studies (Moran et al. (2019) ${ }^{(19)}$ had a $12 \%$ attendance rate among low-income shoppers drawn from a rural supermarket in Maine). Sessions were more likely to be attended by those with higher levels of education. Those currently enrolled in WIC were less likely to attend sessions, perhaps because young children made attendance more difficult, or because they receive nutrition education through the WIC programme. Future iterations of this intervention should include additional strategies to improve attendance, such as providing child care and/or transportation vouchers.

Despite moderate attendance at the education sessions, the average fruit consumption of participants increased by 0.79 cups/d. A review of studies of financial incentives to purchase fruits and vegetables found that the effects on $\mathrm{F} / \mathrm{V}$ intake ranged between 0.11 and $0.24 \mathrm{cups} / \mathrm{d}^{(59)}$. Our findings are consistent with Bowling et al. (2016) ${ }^{(45)}$ and Brimblecombe et al. (2017) ${ }^{(46)}$ who find that pairing financial incentives with nutrition education appears to increase F/V intake, but inconsistent with Moran et al. (2019) ${ }^{(19)}$ who find a combined intervention had no effect on $\mathrm{F} / \mathrm{V}$ intake. Because no participants were randomised to receive the financial incentive only in our study, we cannot definitively state that the larger effect we observe is due to the addition of the education. In particular, the larger effect may be due to the difference in incentive amount; most incentives in the literature range from a $12 \%$ to a $50 \%$ discount on the price of fruits and vegetables, where this intervention included a $100 \%$ discount with a cap of $\$ 10-\$ 20$ per week.

Among studies of the effect of financial incentives on the intake of fruits and vegetables separately, many find that financial incentives increase vegetable intake more than fruit intake ${ }^{(13,45,60)}$. Thus, our results are different based on their effect on fruit intake. The cooking class recipes emphasised fruit more than vegetables (e.g. mango salsa, and apples and raisins in the Moroccan chicken recipe), but the increase in fruit intake is for all participants, not just those who attended the class. Further research is needed to understand why some incentives lead to greater vegetable intake, while others lead to greater fruit intake.

There are some important limitations of this pilot study. First, the sample size is small ( $n$ 120). Second, the intervention does not have a control group. All participants of this study received a fresh produce benefit and were invited to attend both education sessions. As a result, the study cannot truly assess whether the effects observed are due to the intervention, or to some other factor that was experienced by all participants (such as the season changing from winter to early spring when more seasonal fruit becomes available). The changes in outcomes may have also been due to social desirability bias among participants ${ }^{(61)}$. Similarly, the study cannot assess whether the effects of the 
combination of financial incentives and education sessions were greater than either component separately.

Third, participation in the grocery store tour and the cooking class was voluntary. Participants who chose to attend the grocery store tour and/or the cooking class may have already been knowledgeable of shopping strategies, cooking and nutrition. We did not assess cooking skills, confidence or habits at baseline and thus are unable to examine selection into the education components. However, in the follow-up assessment, very few participants attending the tour (5\%) and the cooking class (12\%) indicated that they already did the various skills taught before the tour/class. In any case, the results may overestimate the contribution of the educational programming component of the intervention on the improvement in outcomes.

Fourth, the F/V intake was assessed by only one 24-h dietary recall, whereas the standard is to average three 24-h dietary recalls. The 24-h dietary recalls were conducted online with extensive help from the case managers in a large fraction of cases. Conducting three dietary recalls at both time points using the free online recall system would have greatly reduced our participation rate and increased our attrition rate. However, this is still the first study to our knowledge to use dietary recalls to evaluate the combined effect of financial incentives and education; others examined purchases instead of intake ${ }^{(44,46)}$ or used survey questions about how many times per day foods were eaten $^{(45)}$.

Finally, our measure of BMI is based on self-reported height and weight instead of objective measurements. We only use BMI as a covariate and not as an outcome, but still BMI is likely imprecisely reported with a downward bias.

\section{Conclusions}

Healthy eating can lead to lower health care costs through prevention and better management of chronic diseases such as diabetes and $\mathrm{CVD}^{(3,62)}$. This pilot study finds that combining financial incentives to purchase fruits and vegetables with cooking and nutrition education in a lowincome population recruited at food pantries was highly acceptable, but barriers to attendance of nutrition education sessions need to be addressed in future research. Financial incentives to promote healthy eating is a promising strategy for improving diet quality among low-income households, but more research is needed to make financial incentives more effective at influencing low-income people's purchase and intake of fresh produce.

\section{Acknowledgements}

Acknowledgements: This study could not have happened without numerous members of the community from the
Minnesota Hunger Initiative (Patty Wilder), University of Minnesota Extension Services (CeAnn Klug Verdoorn), University of Minnesota (Lisa Harnack), Community food pantries (Donn Vargas, Peg Keenan, Jessie Billiet, Pat Gau, Clare Brumback, Byron Laher, Alexa Artmann, Kathy Willis, Deisy De Leon Esqueda), Medica Health Plans (Kari Bailey, Rebecca Newhouse), chefs (Thomas Boehmer, Marie Sais, Rebecca Jackson), Solutran (Carmen Nordstrand, Chad Kelly, Cindy Neiderhiser, Sara Kuphal) and Greater Twin Cities United Way (Megan O'Meara, Alyssa Banks). Financial support: This research was funded by Medica Research Institute, grant number 154. The financial incentives provided in this study were funded by the 'Stop the Growl' Cause Campaign launched by the Greater Twin Cities United Way. Conflict of interest: The authors have no conflicts of interest. Authorship: A.F. conceptualised the study, acquired the funding, designed the study, administered and implemented the study, conducted the analysis and wrote the first draft of the manuscript. X.T. assisted in administering and implementing the study; she curated the data, assisted with analysis, and extensively edited the manuscript. H.D. assisted in administering and implementing the study; she assisted in curating the data and conducting analysis, and extensively edited the manuscript. Ethics of buman subject participation: This study was conducted according to the guidelines laid down in the Declaration of Helsinki, and all procedures involving study participants were approved by the Ethics Committee of Quorum Review Institutional Review Board (QR\#31363). Written informed consent was obtained from all subjects.

\section{References}

1. He K, Hu FB, Colditz GA et al. (2004) Changes in intake of fruits and vegetables in relation to risk of obesity and weight gain among middle-aged women. Int J Obes Relat Metab Disord 28, 1569-1574.

2. Fulton SL, McKinley MC, Young IS et al. (2016) The effect of increasing fruit and vegetable consumption on overall diet: a systematic review and meta-analysis. Crit Rev Food Sci Nutr 56, 802-816

3. Dauchet L, Amouyel P, Hercberg S et al. (2006) Fruit and vegetable consumption and risk of coronary heart disease: a meta-analysis of cohort studies. J Nutr 136, 2588-2593.

4. Potter JD (2005) Vegetables, fruit, and cancer. Lancet 366, 527-530.

5. Steptoe A, Perkins-Porras L, McKay C et al. (2003) Psychological factors associated with fruit and vegetable intake and with biomarkers in adults from a low-income neighborhood. Health Psychol 22, 148-155.

6. Mujcic R \& Oswald AJ (2016) Evolution of well-being and happiness after increases in consumption of fruit and vegetables. Am J Public Health 106, 1504-1510.

7. Moore LV \& Thompson FE (2015) Adults meeting fruit and vegetable intake recommendations - United States, 2013. MMWR Morb Mortal Wkly Rep 64, 709-713.

8. Dong D \& Lin B-H (2009) Fruit and Vegetable Consumption by Low-Income Americans: Would a Price Reduction Make a 
Difference? Economic Research Report. Washington DC: U.S. Department of Agriculture, Economic Research Service.

9. Drewnowski A \& Darmon N (2005) Food choices and diet costs: an economic analysis. J Nutr 135, 900-904.

10. Cassady D, Jetter KM \& Culp J (2007) Is price a barrier to eating more fruits and vegetables for low-income families? $\mathrm{J} \mathrm{Am}$ Diet Assoc 107, 1909-1915.

11. Livingstone KM, Burton M, Brown AK et al. (2020) Exploring barriers to meeting recommendations for fruit and vegetable intake among adults in regional areas: a mixed-methods analysis of variations across socio-demographics. Appetite 153, 104750

12. Bartlett S, Klerman J, Olsho L et al. (2014) Evaluation of the Healthy Incentives Pilot (HIP): Final Report. Washington DC: US Department of Agriculture, Food and Nutrition Service.

13. Herman DR, Harrison GG, Afifi AA et al. (2008) Effect of a targeted subsidy on intake of fruits and vegetables among low-income women in the special supplemental nutrition program for women, infants, and children. Am J Public Health 98, 98-105.

14. Phipps EJ, Braitman LE, Stites SD et al. (2015) Impact of a rewards-based incentive program on promoting fruit and vegetable purchases. Am J Public Health 105, 166-172.

15. Harnack L, Oakes J, Elbel B et al. (2016) Effects of subsidies and prohibitions on nutrition in a food benefit program: a randomized clinical trial. JAMA Intern Med 176, 1610-1619.

16. Geliebter A, Ang I, Bernales-Korins M et al. (2013) Supermarket discounts of low-energy density foods: effects on purchasing, food intake, and body weight. Obesity $\mathbf{2 1}$, 542-548.

17. Kral TVE, Bannon AL \& Moore RH (2016) Effects of financial incentives for the purchase of healthy groceries on dietary intake and weight outcomes among older adults: a randomized pilot study. Appetite 100, 110-117.

18. Polacsek M, Moran A, Thorndike AN et al. (2018) A supermarket double-dollar incentive program increases purchases of fresh fruits and vegetables among low-income families with children: the healthy double study. J Nutr Educ Behav 50, 217-228.

19. Moran A, Thorndike A, Franckle R et al. (2019) Financial incentives increase purchases of fruit and vegetables among lower-income households with children. Health Aff $\mathbf{3 8}$, $1557-1566$.

20. Rummo PE, Noriega D, Parret A et al. (2019) Evaluating a USDA program that gives SNAP participants financial incentives to buy fresh produce in supermarkets. Health Aff (Millwood) 38, 1816-1823.

21. Folland S, Goodman A \& Stano M (editors) (2016) Chapter 9: consumer choice and demand. In The Economics of Health and Health Care, 7th ed, pp. 173-194. New York, NY: Routledge.

22. Wardle, J \& Steptoe A (2003) Socioeconomic differences in attitudes and beliefs about healthy lifestyles. J Epidemiol Community Health 57, 440-443.

23. Dammann KW \& Smith C (2009) Factors affecting lowincome women's food choices and the perceived impact of dietary intake and socioeconomic status on their health and weight. J Nutr Educ Behav 41, 242-253.

24. Tversky A \& Kahneman D (1974) Judgment under uncertainty : heuristics and biases linked references are available on JSTOR for this article : judgment under uncertainty : heuristics and biases. Science 185, 1124-1131.

25. Thaler BRH (2016) Behavioral economics : past, present, and future. Am Econ Rev 106, 1577-1600.

26. Simon HA (2016) Bounded rationality and organizational learning. Science 2, 125-134.

27. Daniel C (2016) Economic constraints on taste formation and the true cost of healthy eating. Soc Sci Med 148, 34-41.
28. Connell PM, Finkelstein SR, Scott ML et al. (2017) Preventing food waste and promoting healthier eating among lowerincome families in industrialized nations. In Handbook Famine, Starvation, Nutrition Deprivation, pp. 1-17 [V Preedy and V Patel, editors]. Cham, Switzerland: Springer.

29. Burton M, Reid M, Worsley A et al. (2017) Food skills confidence and household gatekeepers' dietary practices. Appetite 108, 183-190.

30. Soliah LL, Walter JM \& Jones SA (2012) Benefits and barriers to healthful eating: what are the consequences of decreased food preparation ability? Am J Lifestyle Med 6, 152-158.

31. Lavelle F, McGowan L, Spence M et al. (2016) Barriers and facilitators to cooking from 'scratch' using basic or raw ingredients: a qualitative interview study. Appetite 107, 383-391.

32. Winkler E \& Turrell G (2009) Confidence to cook vegetables and the buying habits of Australian households. J Am Diet Assoc 109, 1759-1768.

33. Taillie LS (2018) Who's cooking? Trends in US home food preparation by gender, education, and race/ethnicity from 2003 to 2016. Nutr J 17, 1-9.

34. Smith LP, Ng SW \& Popkin BM (2013) Trends in US home food preparation and consumption: analysis of national nutrition surveys and time use studies from 1965-1966 to 2007-2008. Nutr J 12, 45.

35. Virudachalam S, Long JA, Harhay MO et al. (2014) Prevalence and patterns of cooking dinner at home in the USA: National Health and Nutrition Examination Survey (NHANES) 2007-2008. Public Health Nutr 17, 1022-1030.

36. Guthrie JF, Lin B-H \& Frazao E (2002) Role of food prepared away from home in the American diet, 1977-78 versus 1994-96: changes and consequences. J Nutr Educ Behav 34, 140-150.

37. Fertig AR, Loth KA, Trofholz AC et al. (2019) Compared to pre-prepared meals, fully and partly home-cooked meals in diverse families with young children are more likely to include nutritious ingredients. J Acad Nutr Diet 119, 818-830.

38. Mills S, White M, Brown H et al. (2017) Health and social determinants and outcomes of home cooking: a systematic review of observational studies. Appetite 111, 116-134.

39. Hutchinson J, Watt JF, Strachan EK et al. (2016) Evaluation of the effectiveness of the Ministry of Food cooking programme on self-reported food consumption and confidence with cooking. Public Health Nutr 19, 3417-3427.

40. Hartmann C, Dohle S \& Siegrist M (2013) Importance of cooking skills for balanced food choices. Appetite 65, 125-131.

41. Wrieden WL, Anderson AS, Longbottom PJ et al. (2007) The impact of a community-based food skills intervention on cooking confidence, food preparation methods and dietary choices - an exploratory trial. Public Health Nutr 10, 203-211.

42. Caspi CE, Davey C, Friebur R et al. (2017) Results of a pilot intervention in food shelves to improve healthy eating and cooking skills among adults experiencing food insecurity. J Hunger Environ Nutr 12, 77-88.

43. Reicks M, Kocher M \& Reeder J (2017) Impact of cooking and home food preparation interventions among adults: a systematic review (2011-2016). J Nutr Educ Behav 50, 148-172.

44. Blakely T, Mhurchu CN, Jiang Y et al. (2011) Do effects of price discounts and nutrition education on food purchases vary by ethnicity, income and education? Results from a randomised, controlled trial. J Epidemiol Commun Health $\mathbf{6 5}$, 902-908.

45. Bowling AB, Moretti M, Ringelheim K et al. (2016) Healthy foods, healthy families: combining incentives and exposure interventions at urban farmers' markets to improve nutrition among recipients of US federal food assistance. Heal Promot Perspect 6, 10-16.

46. Brimblecombe J, Ferguson M, Chatfield MD et al. (2017) Effect of a price discount and consumer education strategy on food and beverage purchases in remote Indigenous 
Australia: a stepped-wedge randomised controlled trial. Lancet Public Heal 2, e82-e95.

47. Solutran (2019) Solutran. https://www.solutran.com/what-wedo/healthcare-solutions/health-wellness-incentives/(accessed December 2020).

48. Cooking Matters: A Long-Term Impact Evaluation. Share our Strength (2016). https://cookingmatters.org/sites/default/ files/CM_LongTermStudy_singlepages.pdf (accessed December 2020).

49. Pooler JA, Morgan RE, Wong K et al. (2017) Cooking matters for adults improves food resource management skills and self-confidence among low-income participants. J Nutr Educ Behav 49, 545-553. doi: 10.1016/j.jneb.2017.04.008.

50. Escoto KH, Laska MN, Larson N et al. (2012) Work hours and perceived time barriers to healthful eating among young adults. Am J Health Behav 36, 786-796.

51. Appelhans BM, Waring ME, Schneider KL et al. (2014) Food preparation supplies predict children's family meal and home-prepared dinner consumption in low-income households. Appetite 76, 1-8.

52. ASA2 $4^{\circledR}$ Dietary Assessment Tool | EGRP/DCCPS/NCI/NIH (2020) Overview of the Automated Self-Administered 24Hour (ASA24) Dietary Assessment Tool. National Cancer Institute, Division of Cancer Control \& Population Sciences. https://epi.grants.cancer.gov/asa24/ (accessed December 2020).

53. Thompson FE, Dixit-Joshi S, Potischman N et al. (2015) Comparison of interviewer-administered and automated self-administered 24-h dietary recalls in 3 diverse integrated health systems. Am J Epidemiol 181, 970-978.

54. Pannucci TRE, Thompson FE, Bailey RL et al. (2018) Comparing reported dietary supplement intakes between two 24-h recall methods: the Automated Self-administered 24-h Dietary Assessment Tool (ASA24) and the interviewadministered Automated Multiple Pass Method (AMPM). J Acad Nutr Diet 118, 1080-1086.

55. Park Y, Dodd KW, Kipnis V et al. (2018) Comparison of self-reported dietary intakes from the Automated SelfAdministered 24-h recall, 4-d food records, and foodfrequency questionnaires against recovery biomarkers. $\mathrm{Am}$ J Clin Nutr 107, 80-93.

56. Baranowski T (2013) Chapter 4, 24-h recall and diet record methods. Nutritional Epidemiology, 3rd ed. New York: Oxford University Press.

57. Rustad C \& Smith C (2013) Nutrition knowledge and associated behavior changes in a holistic, short-term nutrition education intervention with low-income women. J Nutr Educ Behav 45, 490-498.

58. Polit DF \& Gillespie BM (2010) Intention-to-treat in randomized controlled trials: recommendations for a total trial strategy. Res Nurs Health 33, 355-368.

59. Healthy Food America (2019) Healthy Food Pricing Incentives: A Systematic Review of Current Evidence. Seattle, WA: Healthy Food America. healthyfoodamerica. org (accessed December 2020).

60. Kral TVE, Bannon AL \& Moore RH (2016) Effects of financial incentives for the purchase of healthy groceries on dietary intake and weight outcomes among older adults: a randomized pilot study. Appetite 100, 110-117.

61. Hebert JR, Clemow L, Pbert L et al. (1995) Social desirability bias in dietary self-report may compromise the validity of dietary intake measures. Int J Epidemiol 24, 389-398.

62. Slavin JL \& Lloyd B (2012) Health benefits of fruits and vegetables. Adv Nutr 3, 506-516. 